\title{
The combined effect of bottom-up and top-down factors on life history and reproduction of Daphnia in the field: is a strategic dilemma underlying population declines?
}

\author{
Stephan HÜLSMANN \\ Technische Universität Dresden, Institute of Hydrobiology, 01062 Dresden, Germany \\ e-mail: stephan.huelsmann@tu-dresden.de
}

\begin{abstract}
In a detailed field study covering three years, population dynamics, life history shifts and reproductive patterns of a population of Daphnia galeata were investigated in relation to food availability and dynamics of young of the year fish, the main vertebrate predators. In all years an increase of Daphnia abundance in spring was associated with declining food conditions (clear water stage). The size at maturity (SAM) during this period was high and even increased, brood size declined, while egg volume increased. These patterns may be explained as response to food limitation. A decline of Daphnia abundance in every year was associated with increasing food conditions and the end of the clear water stage. Egg volumes as well as the size of egg-carrying daphnids also decreased, while brood size remained at low values. In two years in which these changes were particularly pronounced, the available fish data suggest that both the biomass (determining predation pressure), as well as the size of the fish (determining size selection) are important for the observed dynamics. No decrease of SAM occurred as long as fish were smaller than $25 \mathrm{~mm} T L$, when they are still gape-limited and not able to feed on the largest size-classes of Daphnia. Although fish biomass, which should correspond to kairomone level, would have suggested a reduction of SAM as induced defence, probably the selection of small (egg-carrying) daphnids by small fish, besides severe food limitation, prevented this response to become effective. The sudden decline of SAM at the end of the clear water stage may not be explained by gradual phenotypic responses or indirect demographic effects, but must be due to an alternation of generations. SAM may be further reduced by direct and indirect effects of predation, interacting with increasing food levels. The Daphnia population is most vulnerable to predation at the time when the new generation takes over. Consequently, predation impact depends on timing of both age-0 fish consumption and feeding selectivity.
\end{abstract}

Key words: size at maturity, egg size, clutch size, fecundity, YOY fish, food limitation

\section{INTRODUCTION}

In aquatic food webs it is a long-standing paradigm that herbivorous zooplankton in the temperate region is controlled by a combination of top-down and bottom-up forces during spring and summer (Sommer et al. 1986), while the relative importance of both forces is still under debate. However, not only zooplankton dynamics are affected, but also strong seasonal changes in the size structure of zooplankton communities and within communities, of Daphnia populations have frequently been reported (Threlkeld 1979b; Vijverberg \& Richter 1982; Lampert 1993; Hülsmann \& Wagner 2007). These were either attributed to food conditions (Threlkeld 1976; Lampert 1988), size selective predation (Vijverberg \& Richter 1982; Cerný \& Bytel 1991) or a combination of both factors (Hülsmann 2001). Predation not only directly via selective elimination of large individuals (Brooks \& Dodson 1965) may shift community composition and population structure. As an indirect effect of size selective predation by fish, the proportion of small first brood eggs will be increased. Since small eggs will result in small neonate size and a small size at maturity, large seasonal variation in population size-structure may be explained by this mechanism (Lampert 1993). More- over, infochemicals (kairomones) of fish were shown to phenotypically induce a reduction of age and size at maturity and and of egg size (Machácek 1991; Lampert 1993; Reede 1995).

Also effects of food limitation on Daphnia life history are well-known: Age at maturity is delayed and size at maturity (SAM) is reduced at low food conditions (Vanni \& Lampert 1992; Boersma \& Vijverberg 1994). However, when food limitation is strong, SAM may also increase (McCauley et al. 1990) or it may be overestimated methodically (Stibor \& Lampert 1993). Food deficiency also induces a decrease in brood size, whereas the size of the eggs increases (Guisande \& Gliwicz 1992; Trubetskova \& Lampert 1995). Phenotypic responses to food limitation and especially reproductive strategies (few, but large eggs) are thus just opposite to strategies known in response to fish predation (small eggs, higher clutch size at given length). Indeed, laboratory studies clearly indicate an interaction of both factors (Hülsmann et al. 2004; Gliwicz \& Maszczyk 2007). These studies suggest that responses to fish are not displayed under severe food limitation. What is largely lacking as of yet, however, are detailed field studies including the quantification of reproductive strategies, food conditions and fish predation to see how 
bottom-up and top-down factors interactively shape phenotypic life history responses in the field.

A detailed field study provided the opportunity to do just that: In Bautzen Reservoir (Saxony, Germany) the zooplankton community is clearly dominated by $D$. galeata throughout the season (Benndorf et al. 1988). A clear-water stage with low food conditions regularly develops in May, lasting for about 4 to 6 weeks (Hülsmann \& Wagner 2007). Young-of-the-year (YOY) fish (mainly perch), the main vertebrate predators, hatch in late April or the beginning of May. Depending on their growth, fish start feeding on daphnids some weeks later when their gape-size is big enough (Mehner et al. 1998a, b; Wagner et al. 2004). We found in several years that this period of increased fish predation coincides with food limitation during the clear water stage. Daphnids might thus face a conflict between a food-deficiency-strategy (delayed maturity, large eggs) and a predation-avoidance-strategy (young age and small size at maturity, small eggs). Due to the morphometric and physical characteristics of Bautzen Reservoir, a hypolimnetic refuge is only partly available (Hülsmann \& Wagner 2007) and also the littoral provides no protection. Consequently, life history adaptations must be regarded as key strategies to minimise predation effects (compare also Sakwinska \& Dawidowicz 2005).

The main research question of this investigation is how daphnids react to this combination of bottom-up and top-down factors concerning their life history and reproductive strategies and how fast the reactions take place. An attempt is made to relate changes in life history and reproduction of $D$. galeata to food conditions and predation by juvenile fish. Finally, with respect to the Daphnia dynamics after the clear water stage (decline or not), the success of the adaptations is evaluated. I hypothesize that food limitation during the clear water stage would constrain life history shifts in response to fish.

\section{METHODS}

The field study was performed in Bautzen Reservoir, situated $c a 60 \mathrm{~km}$ northeast of Dresden, Germany $\left(51^{\circ} 12^{\prime} 51 \mathrm{~N}, 14^{\circ} 27^{\prime} 30 \mathrm{E}\right)$. Due do its morphometric characteristics (maximum depth $12 \mathrm{~m}$, mean depth 7.4 $\mathrm{m}$, surface area $176 \mathrm{ha}$, wind exposed site) thermal stratification is usually week and unstable (Hülsmann \& Wagner 2007). As a result of long-term biomanipulation (Benndorf et al. 2002) the proportion of planktivorous fish of the total fish community biomass declined, $D$. galeata became the dominant taxon within the zooplankton community throughout the season and youngof-the-year fish (mainly percids) represent the main vertebrate planktivores during the investigation period (Wagner et al. 2004).

Zooplankton and particulate organic carbon (POC) were sampled twice a week from May to July during the study period of 1997-1999 in the pelagic zone of the reservoir. Samples were taken with a tube sampler (diameter $95 \mathrm{~mm}, 2 \mathrm{~L}$; Limnos, Finland) at 1-m intervals over the whole water column and pooled from three stations with a similar water depth (10-12 m). Zooplankton organisms were retained by a $30 \mu \mathrm{m}$ net and stored in sugar-formaldehyde for further analysis. The filtrate $(<30 \mu \mathrm{m})$ was used for analysing the edible fraction of POC. Secchi depth was recorded; for the conditions in Bautzen Reservoir, a clear-water stage was defined as a period when Secchi depth exceeds $2.5 \mathrm{~m}$. Data on Daphnia abundance, size structure and POC are partly taken from earlier publications (Hülsmann \& Weiler 2000; Hülsmann 2001; Hülsmann \& Voigt 2002; Hülsmann 2003). YOY fish were sampled in 1997 and 1998 weekly at night using Bongo or a small trawl net. No YOY fish data are available for 1999. Details of the sampling and the basic data are given in Wagner et al. (2004). Here, I refrain from giving the exact dynamics, but only indicate periods when YOY fish biomass, consisting predominantly of YOY perch, exceeded $200 \mathrm{mg} \mathrm{ww} \mathrm{m}^{-3}$. With a depth of roughly $10 \mathrm{~m}$ in the pelagic zone, this value corresponds to about 20 $\mathrm{kg} \mathrm{ha}{ }^{-1}$, which was found to be a threshold value of YOY fish density above which strong effects on Daphnia can be expected (Mills \& Forney 1983). Daphnids from zooplankton samples were enumerated in at least three subsamples. About 100 individuals were measured and the number of eggs in the brood pouch was recorded. SAM was determined according to Stibor \& Lampert (1993). The egg size was measured for all clutches with eggs in developmental stage I (egg membrane intact, compare Threlkeld 1979a). Height $(h)$ and width $(b)$ of one egg per clutch was measured and egg volume was calculated according to its geometric shape (rotated ellipsoid):

$$
V=1 / 6 \pi h b^{2}
$$

Intra-clutch variability in egg size is small (McKee 1997) and was checked regularly during the measurements.

\section{RESULTS}

In all the years of this investigation there was a phase of high Daphnia densities during the study period from May to July, which was associated with low POC values and high Secchi depth readings (peak values $>5$ $\mathrm{m}$ during the clear-water stage, Fig. 1). In 1997 and 1998 the population development in May started from relatively high densities ( 35 and 45 ind $\mathrm{L}^{-1}$, respectively) and increased about threefold in one week. With some fluctuations abundance remained high for about four weeks and then declined rapidly to low values $(\sim 10$ ind $\mathrm{L}^{-1}$ in $1997,<1$ ind $\mathrm{L}^{-1}$ in 1998) which lasted until the end of the investigation period. By contrast, in 1999 abundance increased slowly in spring and started from low densities in early May $\left(<10\right.$ ind $\left.\mathrm{L}^{-1}\right)$. There was not such a clear peak and subsequent decline in density as in 


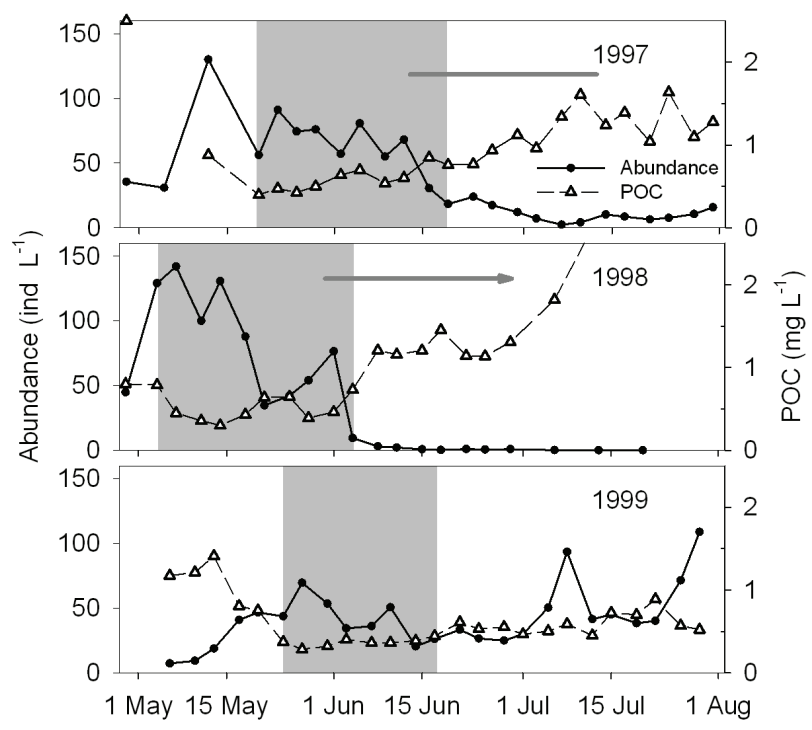

Fig. 1. Temporal pattern of abundance (ind $\left.\mathrm{L}^{-1}\right)$ of $D$. galeata and of $\mathrm{POC}<30 \mu \mathrm{m}\left(\mathrm{mg} \mathrm{L}^{-1}\right)$ in Bautzen Reservoir during the investigation period of 1997, 1998 and 1999. Grey boxes indicate the clear-water stage with Secchi depth $>2.5 \mathrm{~m}$. For 1997 and 1998 additional horizontal lines indicate the period when YOY fish biomass exceeded $200 \mathrm{mg} \mathrm{ww} \mathrm{m}^{-3}$, which in 1998 continued until the end of the investigation period.

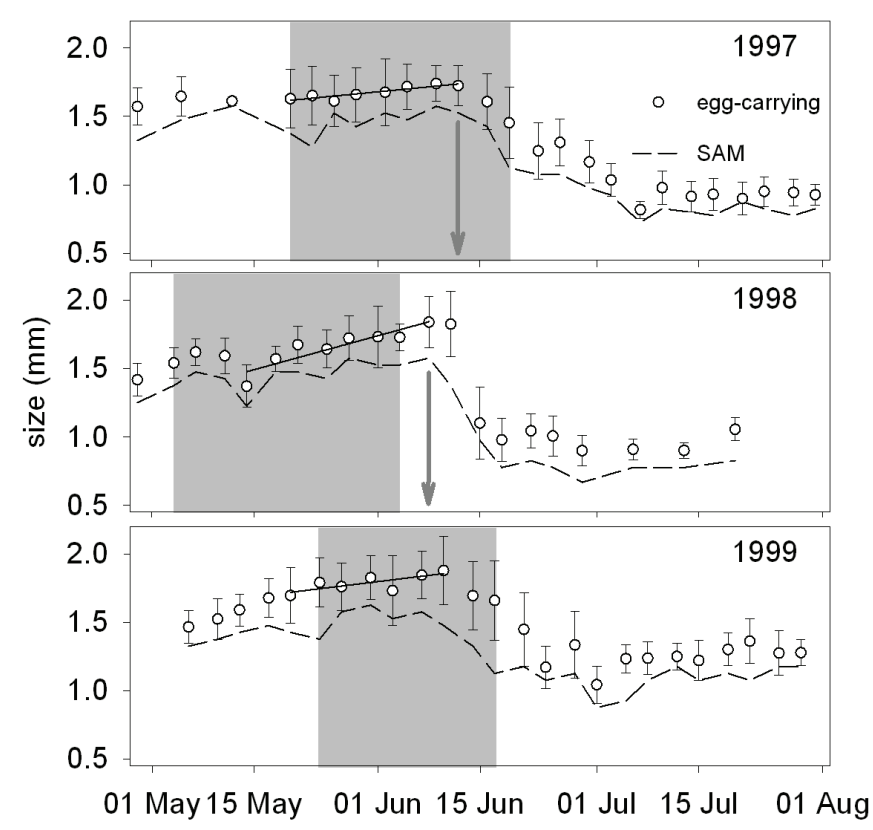

Fig. 2. Temporal pattern of mean size ( $\pm \mathrm{SD}$ ) of egg-carrying females $(\mathrm{mm})$ and of size at maturity (SAM) of the Daphnia population in Bautzen Reservoir during the investigation period of 1997, 1998 and 1999. A linear regression of mean size of egg-carrying daphnids versus time was calculated for periods approximately representing the clear-water stage (indicated by grey boxes) in each year. See table 1 for more details. The vertical arrows indicate the point in time when YOY perch exceed a TL of $25 \mathrm{~mm}$ in 1997 and 1998, indicating a switch in prey selection to large prey sizes (see text).

the former years, but Daphnia abundance remained on a high level and even increased later in summer. POC values strongly increased simultaneously to the decrease in Daphnia abundance in 1997 and 1998, but remained on a much lower level throughout the investigation period in 1999. In that year, after a conspicuous drop in Secchi depth (from about 5 to $2 \mathrm{~m}$ ), values increased again and fluctuated around the threshold value of 2.5 m. Both in 1997 and 1998 YOY fish biomass increased beyond a value of $200 \mathrm{mg} \mathrm{ww} \mathrm{m}^{-3}$ at the end of the clear water stage, no data are available for 1999.

Changes in the size structure of the population were analysed using the data on mean size of egg-carrying daphnids (Fig. 2), the pattern of which was closely followed by SAM. An increase of the size of egg-carrying daphnids and SAM during the clear-water stage is 
Tab. 1. Changes in the size structure of the population of D. galeata in Bautzen Reservoir during the summer of 1997, 1998 and 1999 as shown in figure 2. A linear regression between the development of the mean size of egg-carrying females and time was calculated using the following periods: 20 May-12 June 1997, 14 May-8 June 1998, 20 May-10 June 1999. These periods largely correspond to the clear-water stages of each year, but were defined primarily based on size-frequency distributions of Daphnia indicating one cohort of adults. Mean values of these periods were compared with mean summer values, considering the periods 7-31 July 1997, 18 June-20 July 1998 and 1-29 July 1999, when size of egg-carrying females was stable on a low level. Transitional phases with declining sizes were not considered.

\begin{tabular}{ccccccc}
\hline Year & $\begin{array}{c}\text { Increase per day } \\
(\mu \mathrm{m})\end{array}$ & $r^{2}$ & $p$ & $\mathrm{n}$ & $\begin{array}{c}\text { Mean size clear-water } \\
(\mu \mathrm{m} \pm \mathrm{SD})\end{array}$ & $\begin{array}{c}\text { Mean size summer } \\
(\mu \mathrm{m} \pm \mathrm{SD})\end{array}$ \\
\hline 1997 & 5.19 & 0.82 & 0.0019 & 8 & $1699 \pm 175$ & $925 \pm 110$ \\
1998 & 14.61 & 0.81 & 0.0024 & 8 & $1691 \pm 190$ & $974 \pm 137$ \\
1999 & 6.52 & 0.58 & 0.048 & 7 & $1789 \pm 182$ & $1237 \pm 148$ \\
\hline
\end{tabular}

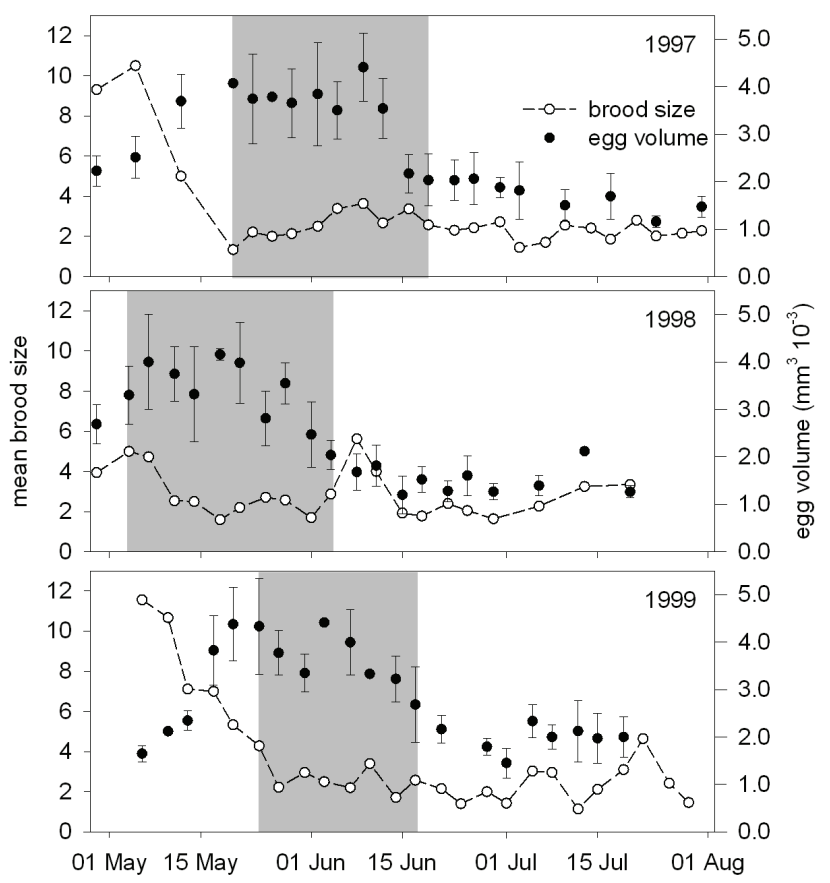

Fig. 3. Temporal development of mean brood size (mean number of eggs per clutch) and mean egg volume $\left(\mathrm{mm}^{3} 10^{-3}\right) \pm \mathrm{SD}$ of $D$. galeata during the investigation period of 1997, 1998 and 1999. Grey boxes indicate the clear-water stage with Secchi depth $>2.5 \mathrm{~m}$.

clearly visible. For periods when size-frequency distributions indicated one cohort of adults to dominate the population, a linear regression was calculated (Tab. 1). Although the slope of the regression size against time was similar in 1997 and 1999, the relation was less clear in the latter year (Tab. 1). The end of the clear water stage in every year was associated with a marked decrease in the size of egg carrying daphnids and of SAM (Fig. 2). Both in 1997 and 1998 this decrease occurred when YOY perch had reached a size of $25 \mathrm{~mm}$ TL, allowing them to feed on the largest size classes of $D$. galeata. In every year mean summer values of the size of ovigerous daphnids were significantly smaller than mean values during the clear-water stage, although the decrease was less marked in 1999 (compare Tab. 1).

When the brood size decreased the mean egg volume (in the sense of egg size, related to single eggs) increased at the same time (Fig. 3) at the beginning of the clear water stage in every year. The egg volume remained high during the first phase of the clear-water stage and declined at the end of this period. Eggs were small during the rest of the summer. Declining egg volumes at the end of the clear water stage were not associated with increasing brood sizes. Plotting egg volume against different variables possibly affecting it (Fig. 4) reveals that eggs were always small when (i) the size off egg-carrying daphnids was small, (ii) food concentration was high and (iii) biomass of juvenile fish was high, which was the typical situation after the clear-water stage. On the other hand, big eggs were only found when large daphnids were present and when food concentration and biomass of juvenile fish was low. The skew of empty symbols in figure 4 towards large egg sizes clearly indicates that these conditions were common during the clear-water stage. However, since eggs may also be small under these conditions, the variables 

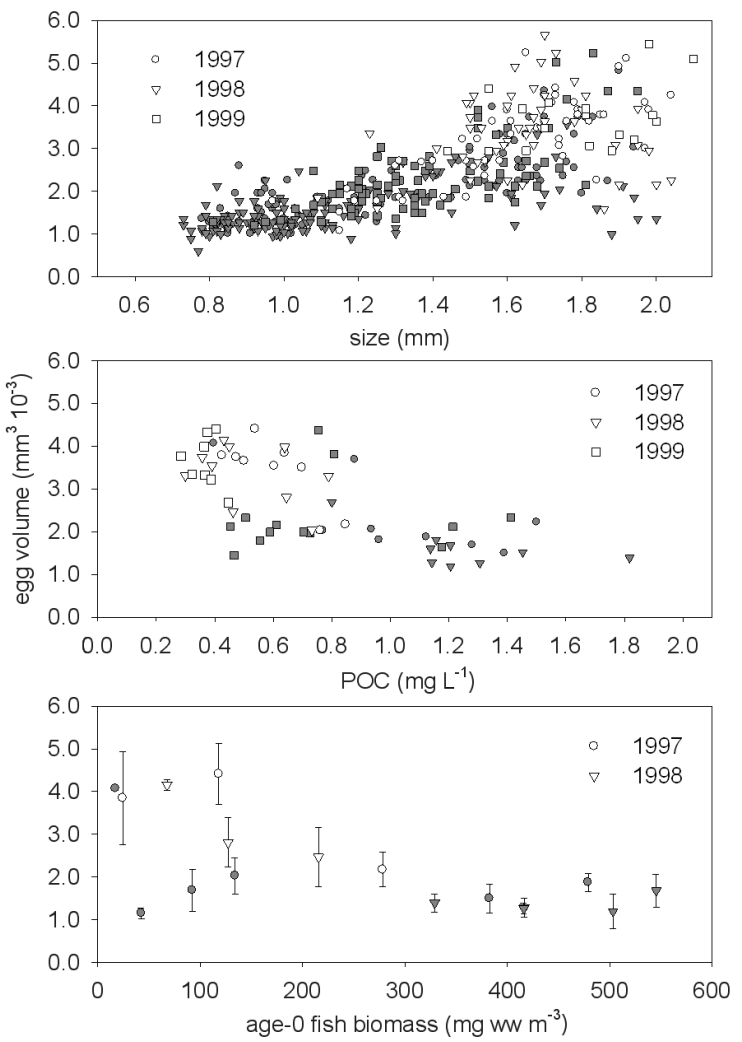

Fig. 4. Dependency of egg volume $\left(\mathrm{mm}^{3} 10^{-3}\right)$ on the body size of egg-carrying individuals of D. galeata (mm; top panel), on food concentration (POC $<30 \mu \mathrm{m}, \mathrm{mg} \mathrm{L}^{-1}$; middle panel) and on age- 0 fish biomass ( $\mathrm{mg} \mathrm{ww} \mathrm{m}^{-3}$; lower panel). In the top panel, the egg volume within single broods is shown whereas in the middle and lower panel mean egg volume of the population per date is provided. SD is shown only in the lower panel but is omitted in the middle panel for clarity. Empty symbols represent values obtained during the clear-water stage, filled symbols represent values obtained before or after this period, respectively.

Daphnia body size, food conditions and fish density (considered separately) only determine the maximum possible egg volume. For a more detailed analysis, figure 5 provides the body size-egg volume relations for single dates at the end of the clear-water stage and for one date later in summer. There was a decrease both of egg volume and body size of egg-carrying females during that period in every year. However, the relation between both parameters differed. In 1997 and 1999 both values gradually declined at the end of the clearwater phase. By contrast, in 1998 egg volume strongly decreased, while body size of egg-carrying females was still high. Both on 4 and 8 June eggs carried by daphnids of $2 \mathrm{~mm}$ length were as small as those carried by daphnids of $1 \mathrm{~mm}$ length later that summer.

\section{DISCUSSION}

The changes in the size structure and in selected life history parameters (SAM, egg volume, brood size) of $D$. galeata demonstrated in this paper may be interpreted as reactions to complex interactions between bottom-up and top-down factors. At the end of the clear water stage both factors strongly interact, eventually preventing effective adaptations of Daphnia, thereby increasing vulnerability which facilitates a population decline.
At the beginning of the clear-water stage, the observed life history changes of the Daphnia population may be attributed exclusively to declining food conditions (juvenile fish biomass at that time is low in any case). This is most obvious for the decrease of fecundity (shown here as mean brood size), which has been shown earlier (Hülsmann 2001). The simultaneous increase of egg volume may be interpreted as a change of reproductive allocation from high quantity offspring production to high quality offspring production, indicating a trade-off between offspring size and number (Ebert 1993). Guisande \& Gliwicz (1992) found that an increase of egg size at decreasing food conditions was associated with increasing lipid content, carbon and mass of the egg. Egg size is positively correlated with neonate size (Guisande \& Gliwicz 1992; Lampert 1993) and larger neonates have a higher survival probability at low food conditions (Tessier \& Consolatti 1989; Guisande \& Gliwicz 1992). However, increasing egg size may also result from increasing size of the mothers (Glazier 1992; Lampert 1993). This effect should be of minor importance at the beginning of the clear-water stage, since body size of egg-carrying females increased mainly towards the end of this period. At that time, egg volume actually decreased (Fig. 3), although food conditions were still bad. Moreover, the relation between 


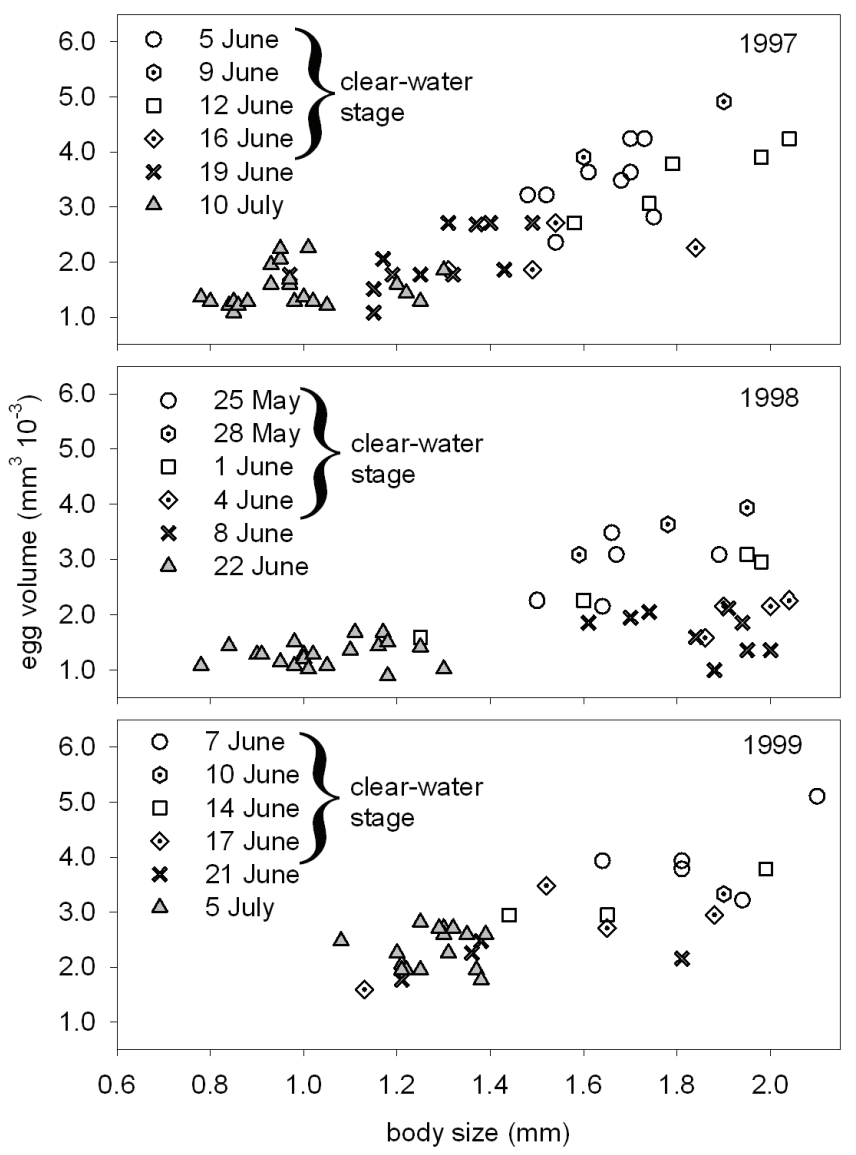

Fig. 5. Relation between body size of egg-carrying daphnids and egg volume (within single broods) at the end of the clear-water stage and later in summer in three successive years in Bautzen Reservoir.

body size and egg volume was different in 1998 compared to 1997 and 1999 (Fig. 5).

Considering results of life table experiments performed under in situ conditions of Bautzen Reservoir during spring and early summer of 1998 and 1999 (Hülsmann \& Voigt 2002) and the development of juvenile fish during this period (Wagner et al. 2004; Hülsmann et al., submitted), it is possible to interpret the reproductive patterns which can be seen in the size patterns and in patterns of reproductive allocation. Daphnids which mature shortly before food conditions decline mostly die after having released their first brood (with small eggs). This was obvious in the first life table experiment in 1999 (Hülsmann \& Voigt 2002). Those daphnids that become adult at the beginning of the clear-water stage have a low fecundity and long time lags between successive broods. These adults continue to reproduce at a low level (that is, few, but large eggs) throughout the clear-water stage and increase in size. Recruitment of adults from juvenile stages is very low during this period, since only few neonates are produced, juvenile growth is reduced and age at maturity is extremely retarded. Daphnids born during this period of low food conditions have their first brood at the end of the clear-water stage, their fecundity responding to any slight and short-term increase in food availability. First- brood eggs are generally smaller than those from later broods (Glazier 1992; Lampert 1993). Consequently, this mechanism may explain the decrease in egg size at the end of the clear-water stage in 1997 and 1999. The size of egg-carrying daphnids also declined at that time, indicating that indeed these younger daphnids produced those small eggs (Fig. 5). However, in 1998 egg size declined while body size of ovigerous females remained high and it is very unlikely that individuals of $D$. galeata mature only at a size of $1.8-2.0 \mathrm{~mm}$. Probably, at that time fish kairomones were more important than in other years due to the very high biomass of juvenile fish (Wagner et al. 2004), because adult daphnids, when exposed to fish kairomones, produce smaller eggs (Machácek 1995).

After the clear water stage, the different factors influencing egg size (body size, food conditions, fish kairomones) strongly interact: High biomass of juvenile fish (as main factor, Wagner et al. 2004) causes low densities of small-bodied daphnids, unable to control phytoplankton biomass, which results in high POC concentrations. All these factors promote small eggs. The fact that clutch size did not respond accordingly to increasing food conditions (no clear increase after clear water stage) is mainly due to changes in Daphnia size structure. A drastic reduction of the size of egg-carrying 
daphnids also means smaller clutches. Under such circumstances clutch size may not be used as a measure of food limitation (Hülsmann 2001).

The regressions of the size of egg-carrying daphnids versus time suggest that only one cohort of adults dominates the population during the clear-water stage (Fig. 2, Tab. 1). This was most clearly in 1997 and 1998, less so in 1999. This interpretation is in line with conclusions drawn from different recruitment patterns in single years (Hülsmann 2003). In 1997 and 1998 (with midsummer decline) adult daphnids dominating the population during the clear-water stage really represent a cohort because they were born during a short time interval of about one week. By contrast, in 1999 (no midsummer decline) recruitment per unit time was continuously low. Consequently, the range in age of the adult daphnids during the clear-water phase should be larger, although in principal the same mechanisms work during this period as in years with midsummer decline.

At the end of the clear-water stage changes in the size structure of the Daphnia population obviously are not only influenced by food conditions. Instead, predation is more likely to be responsible for the observed size changes in summer (compare Gliwicz \& Boavida 1996). Thus, it can be concluded that a strong reduction of SAM only occurs at high biomasses of juvenile fish in Bautzen Reservoir (Hülsmann \& Wagner 2007), which means that only a moderate fish biomass must be assumed for 1999 .

The timing of population dynamics, life history adaptations and bottom-up and top-down factors at the end of the clear-water stage in different years (19971999) can be summarised in the following way:

- increasing POC concentrations (edible fraction) were recorded at the same time as the decline of Daphnia density, always preceding the end of the clear-water stage;

- egg volume and Daphnia abundance decreased simultaneously;

- SAM decreased with a short (3-4 days) delay in 1997 and 1999, whereas in 1998 SAM declined one week after the decline of Daphnia density;

- the decline of Daphnia density in 1997 and 1998 started after the biomass of juvenile fish exceeded $200 \mathrm{mg} \mathrm{ww} \mathrm{m}^{-3}$; in both years this decline was correlated with a decrease of SAM and occurred when YOY perch had reached $25 \mathrm{~mm}$ TL, a size allowing them to feed also on the largest size classes of Daphnia.

If it is assumed that small egg sizes are a prerequisite for small SAM (Lampert 1993), SAM should be reduced with a time lag corresponding to juvenile development time. Bearing in mind the juvenile development times from the life table experiments (minimum age at maturity $11 \mathrm{~d}$ even after the clear-water phase, (Hülsmann \& Voigt 2002), it gets clear that the decrease in egg size may not explain the fast decrease of SAM. Instead, results from life table experiments suggest that the initiation of this decrease was due to an alternation in generations. Daphnids born during the clear-water stage had their first (very retarded) brood exactly at the end of this period. Only at that time (when food conditions eventually already increased) had they accumulated enough energy to produce their first clutch. Compared to the cohort of adults, which was present during the clear-water stage, these animals were significantly smaller (about $1.3 \mathrm{~mm}$ ). This may similarly be seen in size data (Fig. 2) and deduced from growth curves of daphnids from life table experiments (Hülsmann \& Voigt 2002). Their broods consisted of small eggs, which hatched to small neonates, which (at least in 1997 and 1998) were exposed to high food conditions and high kairomone concentrations. All these factors favour small SAM, explaining the further decrease.

Concerning the timing of life history adaptations, the reduction of SAM in 1998 was delayed compared to 1997 and 1999, when it declined simultaneously with Daphnia density. This delay is surprising since kairomone effects of juvenile fish (Hülsmann et al. 2004) should be expected especially in this year. In 1998 SAM decreased only when Daphnia density was already very low, however, the reduction occurred even faster than in other years. This may be explained by the feeding strategies of juvenile fish. While fish grow during their early development, they subsequently feed on larger prey as their mouth gape becomes bigger (Hansen \& Wahl 1981; Mehner et al. 1998b).

Investigations of food selection of perch and zander in Bautzen Reservoir showed that they feed on smaller than average-sized daphnids as long as they are smaller than $25 \mathrm{~mm}$ in total length (TL) which can be expected during the clear-water stage (Mehner et al. 1998b). Laboratory experiments with juvenile perch feeding on Daphnia showed the same results (Hülsmann et al., submitted). Perch smaller than $25 \mathrm{~mm}$ TL selected small and medium sized daphnids $(<1.5 \mathrm{~mm})$, whereas larger fish strongly selected larger prey sizes.

However, besides Daphnia size the presence of eggs influenced prey selection. Perch $\geq 19 \mathrm{~mm}$ TL started selecting egg-carrying daphnids of medium size and fed on such individuals although they could not be found in zooplankton samples (with more than 100 daphnids measured). When perch grew larger ( $>25 \mathrm{~mm} \mathrm{TL}$ ), they strongly selected egg-carrying daphnids from all size classes. Both in 1997 and in 1998 the mean length of juvenile perch reached $25 \mathrm{~mm}$ TL exactly at that date when SAM was high for the last time (Hülsmann et al., submitted, see also Fig. 2). This means that before this date, daphnids that matured at a smaller size were strongly selected by perch. There might have been some daphnids that became mature at a smaller size at the end of the clear-water stage in 1998, similar to 1997 and 1999, but they did not show up because fish were 
smarter in finding them. Consequently, a decrease of SAM can only be observed once juvenile percids change their size selection towards larger size classes. When they do so, however, they may accelerate the process of reducing SAM by indirect demographic effects as described by Lampert (1993).

Biomass of juvenile fish was higher in 1998 than 1997 and presumably also in 1999 and it can be assumed that the proposed mechanism of preventing a reduction of SAM only works when feeding pressure of gape-limited fish on daphnids is strong. The combination of food limitation during the clear-water stage and predation (concerning timing, intensity and selectivity) in 1998 seems to represent the worst case for D. galeata in Bautzen Reservoir because the population almost vanished in summer $\left(<1\right.$ ind $\left.\mathrm{L}^{-1}\right)$. By contrast, in 1997, with an also high biomass of juvenile fish, D. galeata stabilised at a low level $\left(\sim 10\right.$ ind $\left.\mathrm{L}^{-1}\right)$ in summer. In that year the timing of size-selection of juvenile fish was slightly different. SAM (observably) decreased simultaneously with Daphnia density and thus, medium-sized daphnids, which were now below the preferred size range of juvenile fish, benefited from increasing food levels during the decline and had a high chance to reproduce successfully (at least once). As can be seen in the size-data on 8 June 1998 (Fig. 2), those large daphnids that were still beyond the ingestible prey size for juvenile fish also responded with increased egg production to increasing food levels. But because fish grew fast and changed their feeding behaviour, it must be assumed that most of these daphnids were eaten before the eggs hatched. Reducing the size at maturity (and offspring size) may allow cladocerans to coexist with high densities of planktivorous fish (Vanni 1987; Lampert 1991), but according to results from Bautzen Reservoir only at low densities (as in 1997). If this strategy is counteracted by a changing feeding selectivity of juvenile fish, such catastrophic crashes as in 1998 cannot be prevented.

\section{CONCLUSIONS}

In summary, life history adaptations of D. galeata strongly respond to changing bottom-up and top-down factors. At the beginning of the clear-water phase, changing food conditions are most important, inducing a change from high quantity (many small eggs) to high quality (few big eggs) reproduction. The population structure during the clear-water phase is dominated by a single cohort of adults, which continue to grow and to reproduce at a low level. The end of the clear-water stage is marked by an alteration of generations. Animals born during this period have their first, very retarded brood with small eggs and at a smaller size compared to the "old" cohort of adults. SAM may be further reduced by direct and indirect effects of predation, interacting with increasing food levels. The Daphnia population is most vulnerable to predation at the time when the new generation takes over. Consequently, predation impact depends on timing of both age- 0 fish consumption and feeding selectivity.

\section{ACKNOWLEDGEMENTS}

Field investigations were only possible in collaboration with many people, especially H. Voigt, W. Weiler, H. Dörner and A. Wagner. T. Mehner and J. Benndorf are acknowledged for support and initiating the project. The work was strongly influenced by discussions with the colleagues mentioned above. Financial support was provided by the Deutsche Forschungsgemeinschaft (DFG) projects Be 1671/2-2, -/2-3.

\section{REFERENCES}

Benndorf, J., H. Schultz, A. Benndorf, R. Unger, E. Penz, H. Kneschke, K. Kossatz, R. Dumke, U. Hornig, R. Kruspe \& S. Reichel. 1988. Food-web manipulation by enhancement of piscivorous fish stocks: Long-term effects in the hypertrophic Bautzen reservoir. Limnologica, 19: 97-110.

Benndorf, J., W. Böing, J. Koop \& I. Neubauer. 2002. Topdown control of phytoplankton: the role of time scale, lake depth and trophic state. Freshwat. Biol., 47: 2282-2295.

Boersma, M. \& J. Vijverberg. 1994. Resource depression in Daphnia galeata, Daphnia cucullata and their interspecific hybrid: life history consequences. J. Plankton Res., 16: 1741-1758.

Brooks, J.L. \& S.I. Dodson. 1965. Predation, body size, and the composition of the plankton. Science, 150: 28-35.

Cerný, M. \& J. Bytel. 1991. Density and size distribution of Daphnia populations at different fish predation levels. Hydrobiologia, 225: 199-208.

Ebert, D. 1993. The trade-off between offspring size and number in Daphnia magna: The influence of genetic, environmental and maternal effects. Arch. Hydrobiol. Suppl., 90: 453-473.

Glazier, D.S. 1992. Effects of food, genotype, and maternal size and age on offspring investment in Daphnia magna. Ecology, 73: 910-926.

Gliwicz, Z.M. \& M.J. Boavida. 1996. Clutch size and body size at first reproduction in Daphnia pulicaria at different levels of food and predation. J. Plankton Res., 18: 863-880.

Gliwicz, Z.M. \& P. Maszczyk. 2007. Daphnia growth is hindered by chemical information on predation risk at high but not at low food levels. Oecologia, 150: 706-715.

Guisande, C. \& M.Z. Gliwicz. 1992. Egg size and clutch size in two Daphnia species grown at different food levels. $J$. Plankton Res., 14: 997-1007.

Hansen, M.J. \& D.H. Wahl. 1981. Selection of small Daphnia pulex by yellow perch fry in Oneida Lake, New York. Trans. Am. Fish. Soc., 110: 64-71.

Hülsmann, S. 2001. Reproductive potential of Daphnia galeata in relation to food conditions: implications of a changing sizestructure of the population. Hydrobiologia, 442: 241-252.

Hülsmann, S. 2003. Recruitment patterns of Daphnia: a key for understanding midsummer declines? Hydrobiologia, 491: 35-46.

Hülsmann, S. \& H. Voigt. 2002. Life-history of Daphnia galeata in a hypertrophic reservoir and consequences of non-consumptive mortality for the initiation of a midsummer decline. Freshwat. Biol., 47: 2313-2324.

Hülsmann, S. \& A. Wagner. 2007. Multiple defence strategies of Daphnia galeata against predation in a weakly stratified reservoir. Hydrobiologia, 594: 187-199.

Hülsmann, S. \& W. Weiler. 2000. Adult, not juvenile mortality as a major reason for the midsummer decline of a Daphnia population. J. Plankton Res., 22: 151-168. 
Hülsmann, S., M. Janßen, A. Wagner \& W.M. Mooij. (2011). Size- and egg-selective feeding in fish-zooplankton interactions: demonstrating a cost of reproduction: (submitted).

Hülsmann, S., J. Vijverberg, M. Boersma \& W.M. Mooij. 2004. Effects of infochemicals released by gape-limited fish on life history traits of Daphnia: a maladaptive response? J. Plankton Res., 26: 535-543.

Lampert, W. 1988. The relative importance of food limitation and predation in the seasonal cycle of two Daphnia species. Verh. Internat. Verein. Limnol., 23: 713-718.

Lampert, W. 1991. The dynamics of Daphnia magna in a shallow lake. Verh. Internat. Verein. Limnol., 24: 795-798.

Lampert, W. 1993. Phenotypic plasticity of the size at first reproduction in Daphnia: the importance of maternal size. Ecology, 74: 1455-1466.

Machácek, J. 1991. Indirect effects of planktivorous fish on the growth and reproduction of Daphnia galeata. Hydrobiologia, 225: 193-197.

Machácek, J. 1995. Inducibility of life history changes by fish kairomones in various developmental stages of Daphnia. J. Plankton Res., 17: 1513-1520.

McCauley, E., W.W. Murdoch \& R.M. Nisbet. 1990. Growth, reproduction, and mortality of Daphnia pulex Leydig: life at low food. Funct. Ecol., 4: 505-514.

McKee, D. 1997. Intra-clutch offspring size variability in the freshwater zooplankter Daphnia magna. Hydrobiologia, 354: 111-117.

Mehner, T., M. Plewa, S. Hülsmann \& S. Worischka. 1998b. Gape-size dependent feeding of age-0 perch (Perca fluviatilis) and age-0 zander (Stizostedion lucioperca) on Daphnia galeata. Arch. Hydrobiol., 142: 191-207.

Mehner, T., S. Hülsmann, S. Worischka, M. Plewa \& J. Benndorf. 1998a. Is the midsummer decline of Daphnia really induced by age- 0 fish predation? Comparison of fish consumption and Daphnia mortality and life history parameters in a biomanipulated reservoir. J. Plankton Res., 20: 1797-1811.

Mills, E.L. \& J.L. Forney. 1983. Impact on Daphnia pulex of predation by young yellow perch in Oneida Lake, New York. Trans. Am. Fish. Soc., 112: 151-161.
Reede, T. 1995. Life history shifts in response to different levels of fish kairomones in Daphnia. J. Plankton Res., 17: 1661-1667.

Sakwinska, O. \& P. Dawidowicz. 2005. Life history strategy and depth selection behavior as alternative anitipredator defenses among natural Daphnia hyalina populations. Limnol. Oceanogr., 50: 1284-1289.

Sommer, U., Z.M. Gliwicz, W. Lampert \& A. Duncan. 1986. The PEG-model of seasonal succession of planktonic events in fresh waters. Arch. Hydrobiol., 106: 433-471.

Stibor, H. \& W. Lampert. 1993. Estimating the size at maturity in field populations of Daphnia (Cladocera). Freshwat. Biol., 30: 433-438.

Tessier, A.J. \& N.L. Consolatti. 1989. Variation in offspring size in Daphnia and consequences for individual fitness. Oikos, 56: 269-276.

Threlkeld, S.T. 1976. Starvation and the size structure of zooplankton communities. Freshwat. Biol., 6: 489-496.

Threlkeld, S.T. 1979a. Estimating cladoceran birth rates: The importance of egg mortality and the egg age distribution. Limnol. Oceanogr., 24: 601-612.

Threlkeld, S.T. 1979b. The midsummer dynamics of two Daphnia species in Wintergreen Lake, Michigan. Ecology, 60: 165-179.

Trubetskova, I. \& W. Lampert. 1995. Egg size and egg mass of Daphnia magna: response to food availability. Hydrobiologia, 307: 139-145.

Vanni, M.J. 1987. Effects of food availability and fish predation on a zooplankton community. Ecol. Monogr., 57: 61-88.

Vanni, M.J. \& W. Lampert. 1992. Food quality effects on life history traits and fitness in the generalist herbivore Daphnia. Oecologia, 92: 48-57.

Vijverberg, J. \& A.F. Richter. 1982. Population dynamics and production of Daphnia hyalina Leydig and Daphnia cucullata Sars in Tjeukemeer. Hydrobiologia, 95: 235-259.

Wagner, A., S. Hülsmann, H. Dörner, M. Janssen, U. Kahl, T. Mehner \& J. Benndorf. 2004. Initiation of the midsummer decline of Daphnia as related to predation, non-consumptive mortality and recruitment: a balance. Arch. Hydrobiol., 160: 1-23. 